\title{
Role of Automatic Tube Compensation as Spontaneous Breathing Trial in Critically Ill Patients: A Systematic Review and Meta-Analysis
}

\author{
Yu Chen ${ }^{1}$, Xu Tian ${ }^{2, \star}$, Chun-Mei Luo ${ }^{1}$, Shu-Lan Luo ${ }^{1}$, Ling Lin ${ }^{1}$, \\ María F. Jiménez-Herrera ${ }^{3, *}$
}

${ }^{1}$ Department of orthopaedics, the Second Affiliated Hospital of Army Medical University, Chongqing,

P. R. China

${ }^{2}$ Department of Gastroenterology, Chongqing University Cancer Hospital, Chongqing, P. R. China

${ }^{3}$ Nursing Department, Universitat Rovira i Virgili, Tarragona, Spain

\section{*Correspondence}

yxtx880919@hotmail.com (Xu Tian)

maria.jimenez@urv.cat

(María F. Jiménez-Herrera)

\begin{abstract}
Objectives: The role of automatic tube compensation (ATC) compared to other spontaneous breathing trials (SBTs) in critically ill receiving mechanical ventilation remains uncertain. The aim of this meta-analysis was to determine the role of ATC in critically ill patients compared to alternative SBT techniques. Methods: We searched PubMed, Cochrane Library, and Embase to capture all potential randomized controlled trials (RCTs) investigating the comparative efficacy of ATC related to other SBT techniques including pressure support (PS), T-piece, continuous positive airway pressure (CPAP) from their inception to February 2020. Primary outcomes were successful extubation rate. Duration of weaning, intensive care unit (ICU) stay, hospital stay, and hospital mortality was regarded as secondary outcomes. We used a risk ratio with accompanying $95 \%$ confidence interval (CI) to express estimates. Reviewer Manager (RevMan) 5.1.0 was used to complete all statistical analyses. Results: We included 13 studies enrolling 1117 patients in the final analysis. Pooled results indicated no significant difference when ATC plus CPAP (ATC/CAPA) compared to PS (6 RCTs; 572 patients; risk ratio [RR], 1.15; 95\% confidence interval [CI], 1.00 to 1.31$)$, ATC versus T-piece (2 RCTs; 157 patients; RR, 1.14; 95\% CI, 0.93 to 1.40), ATC plus PS (ATC/PS) versus PS alone (1 RCTs; 100 patients; RR, 1.15; 95\% CI, 0.98 to 1.35), ATC/CPAP versus CPAP alone (3 RCTs; 247 patients; RR, 1.12; 95\% CI, 0.97 to 1.29) in terms of successful extubation. Additionally, ATC was also not superior to PS, T-piece, or CPAP in improving the rate of reintubation, the duration of weaning, ICU stay, hospital stay, and hospital mortality. Conclusions: Compared to alternative SBT techniques including PSV and T-piece, ATC may have comparable predictive power of successful extubation in critically ill patients. However, a definite conclusion on this topic can not be drawn due to limited data. Therefore, further studies were required to establish our findings due to limited number of eligible studies and small accumulated sample size.
\end{abstract}

\section{Keywords}

Automatic tube compensation, Spontaneous breathing trials, Critical illness, Systematic review, Meta-analysis

\section{Introduction}

Invasive mechanical ventilation has been an important life support approach for critically ill patients in intensive care unit (ICU) [1], which is widely used to treat acute or chronic respiratory failure [2]. However, successful ventilator weaning is the decisive prerequisite of determining the prognosis when patients were recovered to have spontaneous ventilation [3]. Thus, it is critically important to accurately assess the ability of a patient to sustain spontaneous breathing when extubated [4]. Spontaneous breathing trial (SBT) is an effective method to evaluate the autonomic breathing function and then determine whether ventilator weaning should be performed [5].To date, several methods including T-piece test (T-piece), low-level pressure support ventilation (PSV), and continuous positive airway pressure (CPAP) have been used as SBT technique [6]. Moreover, a new technique, automatic tube compensation (ATC), has also been applied to determine when the ventilator weaning can be conducted recently [7].

The mechanism of the ATC is to compensate the airway resistance caused by the trachea catheter, and eventually reduce the extra work of patients' autonomous respiration[8]. Some studies [9-11] suggested that ATC should be preferably prescribed to guide ventilator weaning in critically ill patients. A meta-analysis indicated that ATC plus CPAP (ATC/CPAP) vs CPAP alone or PS increase initial SBT success rate but 


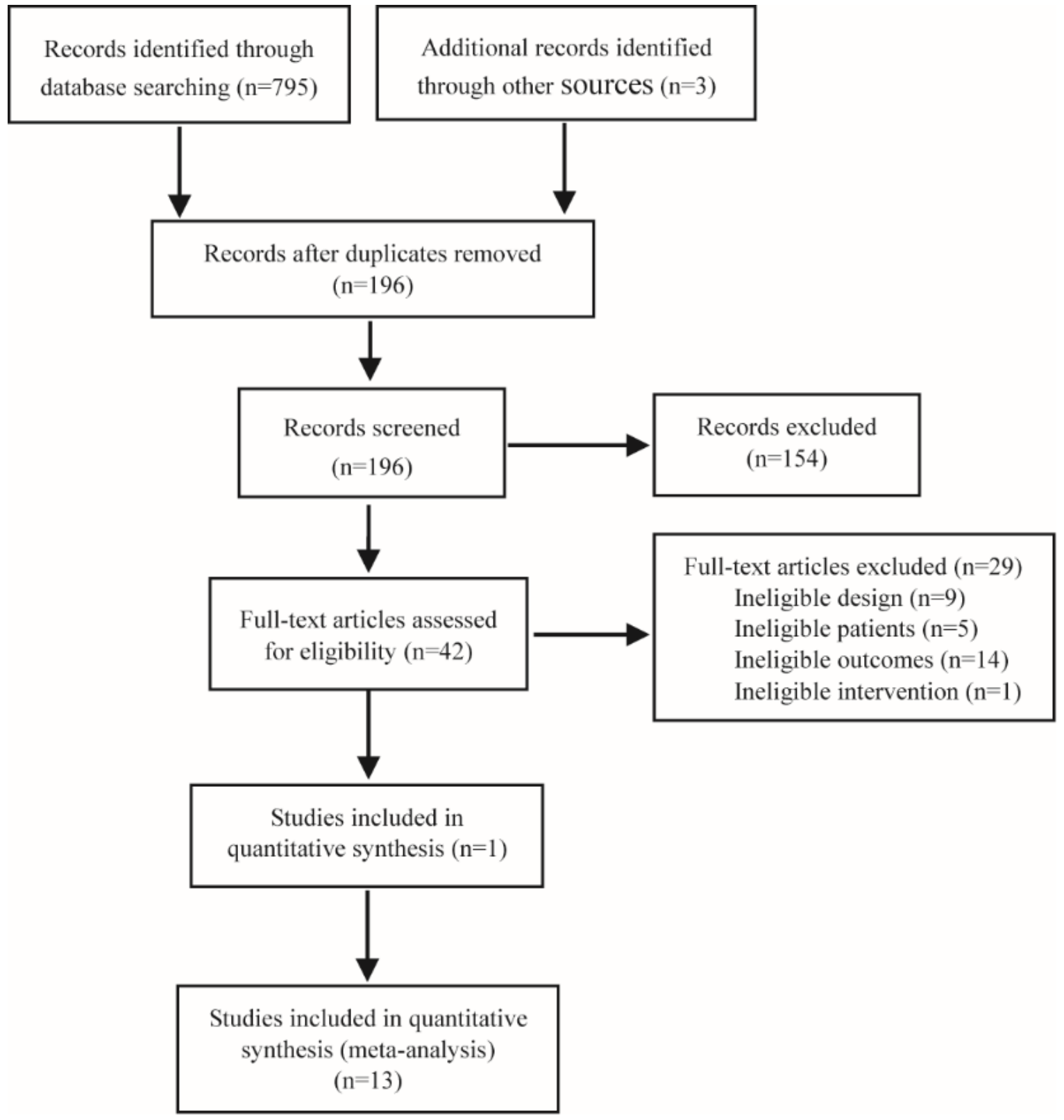

F I G U R E 1. Flow diagram of retrieval and selection of studies.

not extubation success [12]. However, this conclusion was supported by limited data. Moreover, a conclusive consensus on the application of alternative SBT technique has not yet been recommended in guideline [13]. Meanwhile, some potentially eligible studies [10, 11, 14-16] were not included in the final analysis in previous meta-analysis, which impaired the reliability and robustness of summarized results. Thus, it is essential to design further study to determine the comparative efficacy of ATC compared to other alternative SBT techniques. In this systematic review and meta-analysis, we evaluated the comparative efficacy of SBT technique based on ATC and other alternative SBT techniques including T-piece, PSV, and CPAP among critically ill patients.

\section{Methods}

This review was designed according to the framework recommended by Cochrane Collaboration [17]. We reported all results in accordance with the Preferred Reporting Items for Systematic Reviews and Meta-Analyses statement (PRISMA) [18]. Ethical approval was not required for this study because our study was conducted based on published data.

\subsection{Eligibility criteria}

We included randomized controlled trials (RCTs) comparing different SBT techniques in critically ill adult patients. Intervention group was used for SBT technique based on ATC, and control group considered one or more of other SBT techniques including PS, T-piece, CPAP. At least one of the following outcomes should be reported including initial SBT or extubation outcome (success or failure), reintubation, ICU or hospital stay. A study was excluded if it covered at least one of the following criteria: tracheostomized patients; SBTs as part of a weaning strategy; automated SBTs (e.g., SmartCare ${ }^{\mathrm{TM}}$, Intellivent ${ }^{\circledR}$ ); non-invasive ventilation (NIV) vs continued invasive ventilation (CIV); and SBT conduct vs no SBT. 


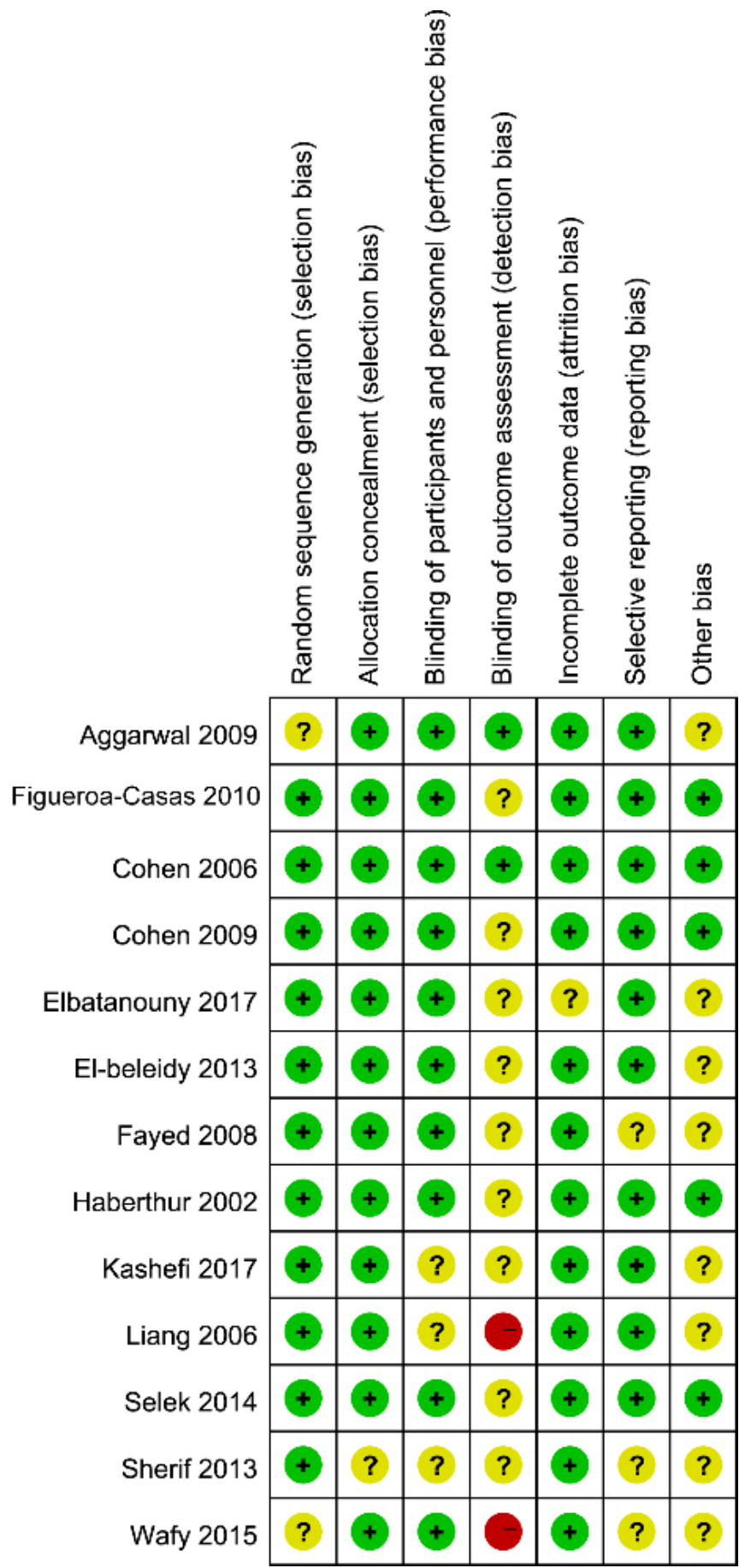

F I G U R E 2. Risk of bias summary.

Green (+), yellow (?), and red (-) represents low, unclear, and high risk of bias.

\subsection{Definition of outcomes}

We regarded successful extubation as primary outcome, which was defined as remaining free of invasive mechanical ventilation $72 \mathrm{~h}$ after the first SBT [19]. Reintubation, the duration of weaning, ICU stay, hospital length of stay, and hospital mortality were defined as secondary outcomes, which were all defined by individual study.

\subsection{Identification of literature}

We searched PubMed, Cochrane Library, and Embase to capture potential citations from their inception to February 2020. No language restriction was imposed. We used MeSH (Medical Subject Heading) and text words to build all search algorithms, which were modified depending on the specific requirements of each database. The following words including "spontaneous breathing trial" or "automatic tube compensation" or "weaning" or "ventilator weaning" or "mechanical ventilation" were used to build search strategies. We also hand checked the bibliography lists of all eligible studies and topic-related reviews to capture any additional studies. Any divergences on retrieval of citations were solved through consulting a third senior investigator.

\subsection{Selection of literature}

We used EndNote software to manage all captured citations. We completed the selection of citations as following three steps. First, we removed duplicate literature through running Finding Duplicate function which was embedded in EndNote software. Second, we excluded all ineligible studies through screening the title and abstract of each literature. Third, we reviewed the full text of each remaining literature after completed step two for checking eligibility. Any divergences on selection were solved through consulting a third senior investigator.

\subsection{Data extraction}

Two authors independently extracted essential data using a standardized form which was developed by the authors in advanced. The following items were extracted: leading author, publication year, country, publication type, the characteristics of patients, details of intervention regimes, sample size, and duration of each session, follow-up (if the patients included were analysed), loss to follow-up (if there was a loss in the sample), outcome measures, presented results. Corresponding author was contacted if any additional information was missed from the full text. Any divergences on data extraction were solved through consulting a third senior investigator.

\subsection{Assessment of risk of bias}

We assigned two investigators to independently appraised the risk of bias of each eligible study using Cochrane Collaboration's risk of bias assessment tool [20] As following seven aspects: randomization sequence, allocation concealment, blinding of study personnel, participants, and outcome assessors, complete reporting of data, selective reporting of bias, and other sources of bias. Individual study was labeled as low risk of bias if an item was met. High risk of bias was labeled if individual study did not fulfill the item. If inadequate information can be used to determine whether individual study meets an item, unclear risk of bias was assigned. Any divergences on risk of bias assessment were solved through consulting a third senior investigator. Moreover, we also grated the quality of each study using the PEDro scale, which covered 11 aspects after completed the Delphi method [21]. One item of the PEDro scale (eligibility criteria) is related to external validity 


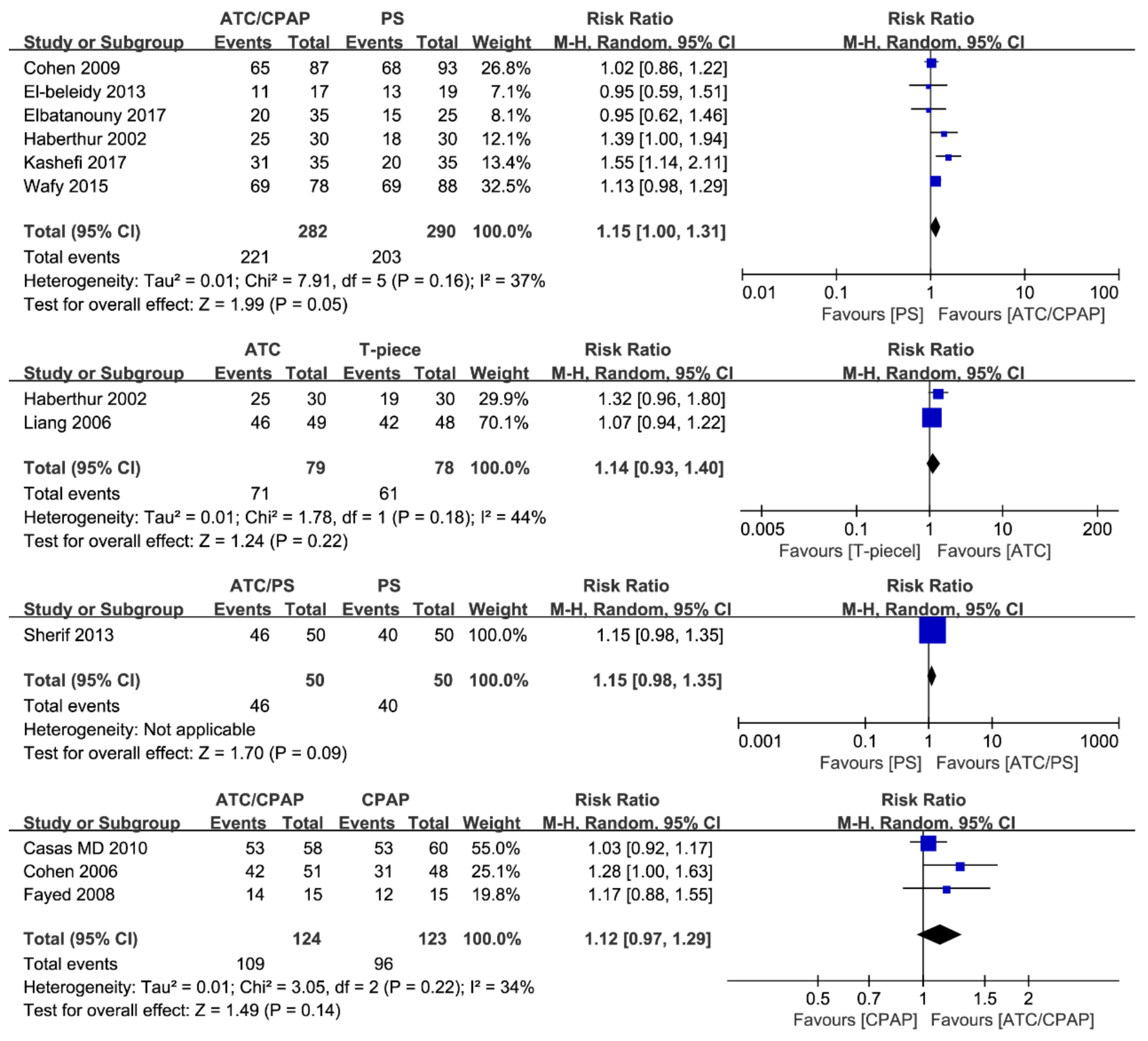

F I G U R E 3. Meta-analysis of successful extubation rate.

ATC, automatic tube compensation; PS, pressure support; CPAP, continuous positive airway pressure; CI, confidence interval.

and thus generally not used to calculate the method score, leaving a total score range of 0 to 10 . The methodological criteria were scored as yes (one point), no (zero point) or unclear (zero point). PEDro score of each selected study provided an indicator of the methodological quality $(9-10=$ excellent; $6-8=$ good; $4-5=$ fair; $<4=$ poor).

\subsection{Statistical assessment}

All statistical analyses in this studywerecompleted with RevMan (Version 5.3. Copenhagen: The Nordic Cochrane Centre, the Cochrane Collaboration, 2014) [17]. We used the risk ratio (RR) with accompanying 95\% confidence interval (CI) to express the estimates of all outcomes. We used Cochrane Q to qualitatively describe the heterogeneity of across eligible studies, and then I square statistic was used to quantitatively estimate the heterogeneity. In this study, we performed all statistical analyses based on the random-effect model because heterogeneity can not be omitted in the real world. We did not qualitatively inspect the publication bias because the accumulated number of eligible studies for individual outcome was more than ten [22].

\section{Results}

\subsection{Identification of literature}

The initial search led to the identification of 798 abstracts, from which 42 studies were considered potentially relevant and retrieved for detailed analysis. After a complete reading of 42 articles, 29 were excluded due to the following reasons: ineligible study design $(n=9)$, ineligible participants $(n=5)$, ineligible outcomes $(\mathrm{n}=14)$, and ineligible intervention $(\mathrm{n}=$ 1), which were all summarized in Supplementary Table 1. 
TABLE 1. Characteristics of the included studies.

\begin{tabular}{|c|c|c|c|c|c|c|c|}
\hline Study & Country & Sample size & Reasons for MV & Duration of MV & Number of reintubation & Regime of intervention & Outcomes \\
\hline Figueroa-Casas 2010 & America & $58 / 60$ & $\begin{array}{l}\text { acute lung injury, multiple } \\
\text { trauma, neurologial, other. ( } \mathrm{p} \\
=0.10)\end{array}$ & $\begin{array}{c}{[(0.05 \pm 0.3) \mathrm{vs}} \\
(0.18 \pm 0.5)] \text { days }\end{array}$ & $\begin{array}{c}3 \text { in ATC/CPAP group vs } 4 \text { in CPAP group } \\
\text { (2 in CPAP group were started on } \\
\text { noninvasive ventilation })\end{array}$ & $\begin{array}{l}\text { ATC/CPAP } 5 \mathrm{cmH} 2 \mathrm{O} \text { vs } \\
\text { CPAP } 5 \mathrm{cmH} 2 \mathrm{O}\end{array}$ & $\mathrm{a}$ \\
\hline Cohen 2006 & Israel & $51 / 48$ & $\begin{array}{l}\text { acute lung injury, } \\
\text { multitrauma, neurological, } \\
\text { other. }(\mathrm{p}=0.53)\end{array}$ & $\begin{array}{l}{[(6.1 \pm 5.1) \text { vs }} \\
(7.1 \pm 5.6)] \text { days }\end{array}$ & $\begin{array}{c}7 \text { in ATC/CPAP group vs } 10 \text { in CAPA } \\
\text { group (all required reintubation, and } 2 \text { vs } 3 \\
\text { were started on noninvasive ventilation in } \\
\text { two groups respectively) }\end{array}$ & $\begin{array}{l}\text { ATC/CPAP } 5 \mathrm{cmH} 2 \mathrm{O} \text { vs } \\
\text { CPAP } 5 \mathrm{cmH} 2 \mathrm{O}\end{array}$ & $a, b$ \\
\hline Fayed 2008 & Egypt & $15 / 15$ & n.a. & n.a. & n.a. & $\begin{array}{l}\text { ATC/CPAP } 5 \mathrm{cmH} 2 \mathrm{O} \text { vs } \\
\text { CPAP } 5 \mathrm{cmH} 2 \mathrm{O}\end{array}$ & a \\
\hline Cohen 2009 & Israel & $87 / 93$ & $\begin{array}{c}\text { acute lung injury, } \\
\text { multi-trauma, COPD } \\
\text { exacerbation, other. }(p=0.15)\end{array}$ & $\begin{array}{l}{[(5.9 \pm 3.5) \text { vs }} \\
(6.3 \pm 4.7)] \text { days }\end{array}$ & $\begin{array}{l}16 \text { in } \mathrm{ATC} / \mathrm{CPAP} \text { group vs } 12 \text { in PS group } \\
\text { (all required reintubation) }\end{array}$ & $\begin{array}{c}\text { ATC/CPAP } 5 \mathrm{cmH} 2 \mathrm{O} \text { vs PS } \\
7 \mathrm{cmH} 2 \mathrm{O}\end{array}$ & $a, b$ \\
\hline El-beleidy 2013 & Egypt & $17 / 19$ & $\begin{array}{l}\text { acute lung injury, } \\
\text { neurological, shock and } \\
\text { sepsis. }(\mathrm{p}=0.08)\end{array}$ & $\begin{array}{c}{[7(2-40) \text { vs }} \\
11(3-30)] \text { days }\end{array}$ & $\begin{array}{c}6 \text { in ATC/CPAP group vs } 6 \text { in PS group } \\
\text { (all required reintubation) }\end{array}$ & $\begin{array}{c}\text { ATC/CPAP } 5 \mathrm{cmH} 2 \mathrm{O} \text { vs PS } \\
6-10 \mathrm{cmH} 2 \mathrm{O}\end{array}$ & $\mathrm{a}$ \\
\hline Elbatanouny 2017 & Egypt & $35 / 25$ & $\begin{array}{l}\text { acute lung injury, traumatic } \\
\text { brain injury, neuromuscular } \\
\text { disease, COPD exacerbation. } \\
\qquad(\mathrm{p}=0.23)\end{array}$ & n.r. & $\begin{array}{l}15 \text { in ATC/CPAP group vs } 10 \text { in PS group } \\
\text { (all required reintubation) }\end{array}$ & $\begin{array}{c}\text { ATC/CPAP } 5 \mathrm{cmH} 2 \mathrm{O} \text { vs PS } \\
\text { (n.s.) }\end{array}$ & a \\
\hline Haberthur 2002 & Switzerland & $30 / 30 / 30$ & $\begin{array}{l}\text { acute lung injury, } \\
\text { neurological, miscellaneous. }\end{array}$ & $\begin{array}{c}{[(142 \pm 127) \text { vs }} \\
(152 \pm 142)] \text { hours }\end{array}$ & $\begin{array}{c}4 \text { in ATC/CPAP group vs } 7 \text { in PS group vs } \\
5 \text { in T-piece group (all } 5 \text { were started on } \\
\text { noninvasive ventilation) }\end{array}$ & $\begin{array}{l}\text { ATC/CPAP } 5 \text { cmH2O vs PS } \\
5 \mathrm{cmH} 2 \mathrm{O} \text { vs T-piece }\end{array}$ & a \\
\hline Wafy $2015^{\S}$ & Egypt & $78 / 88$ & n.a. & n.a. & n.a. & $\begin{array}{l}\text { ATC/CPAP (n.s.) vs PS } \\
\text { (n.s.) }\end{array}$ & $\mathrm{a}, \mathrm{c}$ \\
\hline Kashefi $2017^{\S}$ & Iran & $35 / 35$ & n.a. & n.a. & n.a. & $\begin{array}{l}\text { ATC/CPAP (n.s.) vs PS } 5 \\
\text { cmH } 2 \mathrm{O}\end{array}$ & $\mathrm{a}, \mathrm{c}$ \\
\hline Sherif $2013^{\S}$ & Egypt & $50 / 50$ & n.a. & n.a. & n.a. & ATC/PS vs PS (n.s.) & $\mathrm{a}$ \\
\hline Liang $2006^{\S}$ & China & $49 / 48$ & n.a. & n.a. & n.a. & ATC vs T-piece & $\mathrm{a}$ \\
\hline Selek 2014 & Turkey & $25 / 25$ & $\begin{array}{l}\text { acute lung injury, trauma, } \\
\text { neurological, other. }\end{array}$ & (4.96 vs 7.92 ) days & $\begin{array}{l}7 \text { in } \mathrm{ATC} / \mathrm{PS} \text { group vs } 9 \text { in PS group (all } \\
\text { required reintubation) }\end{array}$ & ATC vs T-piece & $\mathrm{b}, \mathrm{c}$ \\
\hline Aggarwal 2009 & India & $23 / 18$ & $\begin{array}{l}\text { severe neurotoxic snake } \\
\text { envenoming. }\end{array}$ & $\begin{array}{c}{[36.5(23.0-52.0) \text { vs }} \\
41.0(25.0-48.0)] \text { hours }\end{array}$ & none & $\begin{array}{c}\text { ATC/PS } 5 \mathrm{cmH} 2 \mathrm{O} \text { vs PS } 5 \\
\mathrm{cmH} 2 \mathrm{O}\end{array}$ & $b, c, d, e, f$ \\
\hline
\end{tabular}




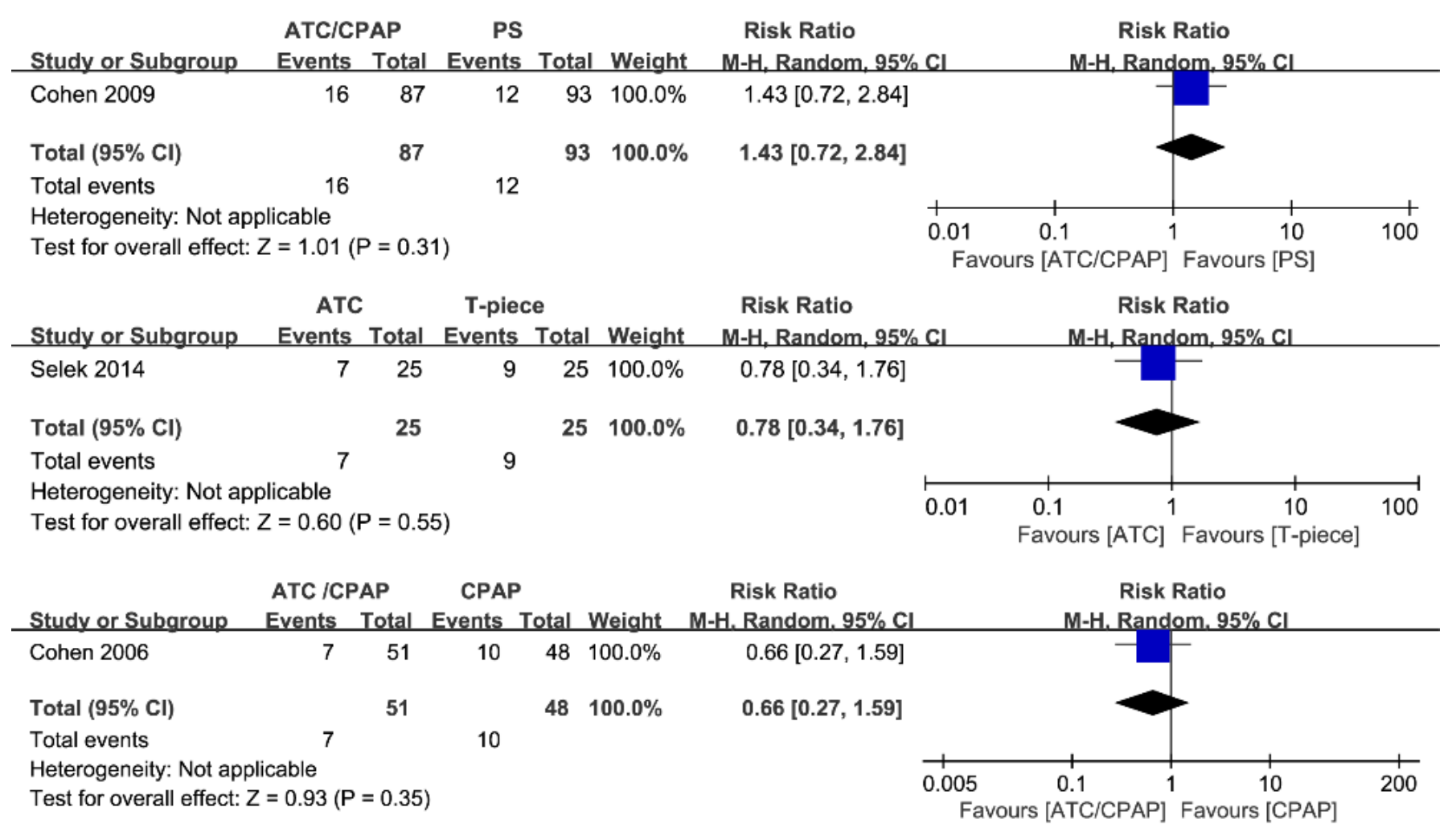

F I G U R E 4. Meta-analysis of reintubation rate.

ATC, automatic tube compensation; PS, pressure support; CPAP, continuous positive airway pressure; CI, confidence interval.

Finally, 13 studies [9-11, 14-16, 23-29] were deemed to meet our inclusion criteria. We designed Fig. 1 to depict the process of study retrieval and selection.

\subsection{Characteristics of all included studies}

The characteristics of the included studies were documented in Table 1. All eligible studies were published between 2006 and 2017. Among these studies, 2 [23, 24] were conducted in Israel, 5 [11, 15, 25, 26, 29] in Egypt, and 1 in Switzerland[9], Iran [10], Turkey [16], China [28], America [27], and India [14] respectively. Sample size of individual study was ranging from 30 to 180 . Four studies [10, 11, 26, 29] were disseminated in abstract, and remaining 9 studies [9, 14-16, 23-25, 27, 28] were published in academic journals in full text. Three studies $[24,26,27]$ reported the comparison of ACT/CPAP and CPAP alone, 7 [9-11, 15, 23, 25, 29] reported the comparison of ACT/CPAP and PS, 2 [16, 28] reported the comparison of ATC and T-piece, and 1 [14] compared ACT/PS with PS alone.

\subsection{Risk of bias}

We drew Fig. 2 to exhibit the results of risk of bias of all eligible studies. Of the 13 eligible studies, 2 [11, 14] did not describe the details of the sequence generation, and 1 [29] study did not conceal the process of allocation. The risks of blinding the participants and personnel among the majority of eligible studies were rated to be low, except for 3 studies [10, 28, 29] which were labeled as unclear risk. Most of the eligible studies did not describe the details of assessing outcomes. Most importantly, 2 studies [11, 28] obviously reported that the blinding of outcome assessors was not performed. Inadequate information can be used to determine whether there was attrition bias in one study [15] Ten studies reported adequate information which can be used to support no selective reporting [9, 10, 14-16, 23-25, 27, 28]. Additionally, we also used the PEDro scale to quantitatively grate the quality of each study and indicated that the overall quality of all studies was fair to good (Table 2).

\subsection{Successful extubation rate}

A total of 12 RCTs [9-11, 15, 16, 23-29] including 1076 patients were included, and the successful extubation rate was about $78.7 \%(847 / 1076)$. Because the interventions were not identical, we divided them into four subgroups. Metaanalysis suggested no significant difference when ATC/CPAP compared to PS (6 RCTs; 572 patients; RR, 1.15; 95\% CI, 1.00 to 1.31 ), ATC compared to T-piece (2 RCTs; 157 patients; RR, 1.14; 95\% CI, 0.93 to 1.40$)$, ATC/PS compared to PS (1 RCT; 100 patients; RR, 1.15 ; 95\% CI, 0.98 to 1.35$)$, ATC/CPAP compared to CPAP (3 RCTs; 247 patients; RR, 1.12; 95\% CI, 0.97 to 1.29 ) in terms of successful extubation rate. In addition, no significant differences were detected when Tpiece compared to PS in the rate of reintubation, duration of weaning, ICU stay, hospital stay, hospital mortality. These pooled results were depicted in Fig. 3.

\subsection{Reintubation rate}

Three of included studies reported the reintubation rate $[16,23,24]$. The reintubation rate was approximately $18.0 \%$ 
TA B L E 2. Study quality on the PEDro scale.

\begin{tabular}{|c|c|c|c|c|c|c|c|c|c|c|c|c|}
\hline Study & 1 & 2 & 3 & 4 & 5 & 6 & 7 & 8 & 9 & 10 & 11 & Total score \\
\hline Figueroa-Casas 2010 [27] & $\sqrt{ }$ & $\sqrt{ }$ & $\sqrt{ }$ & $\sqrt{ }$ & $\times$ & $x$ & $\sqrt{ }$ & $\sqrt{ }$ & $\sqrt{ }$ & $\sqrt{ }$ & $\sqrt{ }$ & 8 \\
\hline Cohen 2006 [13] & $\sqrt{ }$ & $\sqrt{ }$ & $\sqrt{ }$ & $\sqrt{ }$ & $\times$ & $x$ & $\sqrt{ }$ & $\sqrt{ }$ & $\sqrt{ }$ & $\sqrt{ }$ & $\sqrt{ }$ & 8 \\
\hline Fayed 2008 [26] & $\sqrt{ }$ & $\sqrt{ }$ & $\sqrt{ }$ & $x$ & $x$ & $x$ & $x$ & $x$ & $x$ & $\sqrt{ }$ & $\sqrt{ }$ & 4 \\
\hline Cohen 2009 [15] & $\sqrt{ }$ & $\sqrt{ }$ & $\sqrt{ }$ & $\sqrt{ }$ & $x$ & $x$ & $x$ & $\sqrt{ }$ & $\sqrt{ }$ & $\sqrt{ }$ & $\sqrt{ }$ & 8 \\
\hline El-beleidy 2013 [25] & $\sqrt{ }$ & $\sqrt{ }$ & $\sqrt{ }$ & $\sqrt{ }$ & $x$ & $x$ & $\sqrt{ }$ & $\sqrt{ }$ & $x$ & $\sqrt{ }$ & $\sqrt{ }$ & 7 \\
\hline Elbatanouny 2017 [15] & $\sqrt{ }$ & $\sqrt{ }$ & $x$ & $\sqrt{ }$ & $x$ & $x$ & $\sqrt{ }$ & $\sqrt{ }$ & $\sqrt{ }$ & $\sqrt{ }$ & $\sqrt{ }$ & 7 \\
\hline Haberthur 2002 [18] & $\sqrt{ }$ & $\sqrt{ }$ & $\sqrt{ }$ & $\sqrt{ }$ & $x$ & $x$ & $\sqrt{ }$ & $\sqrt{ }$ & $x$ & $\sqrt{ }$ & $\sqrt{ }$ & 7 \\
\hline Wafy 2015 [11] & $\sqrt{ }$ & $\sqrt{ }$ & $\sqrt{ }$ & $x$ & $x$ & $x$ & $x$ & $x$ & $x$ & $\sqrt{ }$ & $\sqrt{ }$ & 4 \\
\hline Kashefi 2017 [10] & $\sqrt{ }$ & $\sqrt{ }$ & $\sqrt{ }$ & $x$ & $x$ & $x$ & $x$ & $x$ & $x$ & $\sqrt{ }$ & $\sqrt{ }$ & 4 \\
\hline Sherif 2013 [21] & $\sqrt{ }$ & $\sqrt{ }$ & $\sqrt{ }$ & $x$ & $x$ & $x$ & $x$ & $x$ & $x$ & $\sqrt{ }$ & $\sqrt{ }$ & 4 \\
\hline Liang 2006 [28] & $\sqrt{ }$ & $\sqrt{ }$ & $x$ & $\sqrt{ }$ & $x$ & $x$ & $\sqrt{ }$ & $\sqrt{ }$ & $x$ & $\times$ & $\sqrt{ }$ & 5 \\
\hline Selek 2014 [16] & $\sqrt{ }$ & $\sqrt{ }$ & $x$ & $\sqrt{ }$ & $x$ & $x$ & $\sqrt{ }$ & $\sqrt{ }$ & $\sqrt{ }$ & $\sqrt{ }$ & $\sqrt{ }$ & 7 \\
\hline Aggarwal 2009 [24] & $\sqrt{ }$ & $\sqrt{ }$ & $x$ & $\sqrt{ }$ & $x$ & $x$ & $\sqrt{ }$ & $\sqrt{ }$ & $\sqrt{ }$ & $\sqrt{ }$ & $\sqrt{ }$ & 7 \\
\hline
\end{tabular}

1, eligibility criteria and source of participants; 2, random allocation; 3, concealed allocation; 4, baseline comparability;

5, blinded participants; 6, blinded therapists; 7, blind assessors; 8, adequate follow-up; 9, intention-to-treat analysis; 10 ,

between-group comparisons; 11, point estimates and variability. Item 1 does not contribute to the total score.

(61/339). Meta-analysis suggested no significant difference when ATC/CPAP versus PS (1 RCT; 180 patients; RR, 1.43; 95\% CI, 0.72 to 2.84), ATC versus T-piece (1 RCT; 50 patients; RR, 0.78 ; 95\% CI, 0.34 to 1.76$)$, ATC/CPAP versus CPAP alone (1 RCT; 99 patients; RR, $0.66 ; 95 \%$ CI, 0.27 to 1.59 ) in terms of reintubation rate. We drew Fig. 4 to depict these pooled results.

\subsection{Duration of weaning}

Three of 13 included studies reported the duration of weaning $[10,11,14]$. There was no significant difference when ATC/CPAP versus PS (MD, -5.94; 95\% CI, -13.10 to 1.21 ) and ATC/PS versus PS alone (MD, $-4.00 ; 95 \% \mathrm{CI},-9.55$ to 1.55 ) in terms of the duration of weaning.

\subsection{Other outcomes}

Of these 13 eligible studies, Aggarwal 2009 [14] reported ICU stay, hospital stay, and hospital mortality as outcomes, however none of the results of these outcomes were clinically significant $(\mathrm{p}>0.05)$.

\section{Discussion}

This systematic review and meta-analysis included 13 eligible studies involving 1117 patients to compare the efficacy of SBT techniques based on ATC with others SBT techniques. Metaanalysis of limited data suggested that SBT techniques based on ATC and other SBT techniques including PSV and T-piece, as SBTs, are considered to have comparable predictive power for successful extubation of critically ill patients.

SBT has been generally used in clinical practice to determine whether the critically ill patients who received mechanical ventilation can successfully separate from ventilator [5]. Published studies suggested that several factors were associated with extubation failure such as upper-airway obstruction, excessive respiratory secretions, and loss of positive pressure in the chest after extubation [30-32].

To date, T-piece and PSV have been used as the common SBT techniques [6]. However, a recent meta-analysis revealed no significant difference in successful extubation rate between the T-piece and PS groups [19]. In recent years, ATC has been developed to assess the possibility of discontinuing mechanical ventilation [8], which was considered to have a similar mechanism with PSV [33]. However, different from PSV, the preset pressure of ATC model can be modified according to the conditions [34]. In the ventilators equipped with ATC, auxiliary pressure that is necessary in order to overcome endotracheal tube resistance is regularly and continuously added to flow-dependent pressure that occurs during respiratory cycle [35]. Therefore, ATC model was deemed to be superior to other SBT techniques. For example, Karaca and colleagues found a beneficial result to ATC plus CPAP compared to CPAP alone [33], which was inconsistent with our finding. It must be noted that only 39 patients were enrolled for the final analysis, however our meta-analysis accumulated more sample size to generate relatively reliable results. Certainly, we considered all critically ill patients who were diagnosed at different conditions in our meta-analysis, so the difference of characteristics inevitably impaired the robustness of pooled results although it increased the generability of our findings. As a result, it hard to obtain a definite conclusion on this issue. In the present study, we found that the successful extubation rate for the whole cohort was $75.9 \%$ in the ATC/CPAP and PSV groups respectively, $78.3 \%$ in the ATC group, and $70.0 \%$ in the PSV group, however all were not statistically significant $(p=0.05)$, which was consistent with the findings of previous meta-analysis [12]. Considering those issues, we suggest further studies with adequate sample size to deeply establish the comparative efficacy of all SBT techniques. 
The main goal of separation from mechanical ventilation is to identify patients who are able to breathe without respiratory assistance with the minimum risk of extubation failure and its potential complications [36]. Daily assessment of spontaneous respiratory function by using SBT techniques may shorten the duration of assisted ventilation [37]. However, we unfortunately found that the rate of reintubation and duration of weaning was no statistically significant difference in this study. It is noted that, in our meta-analysis, only one eligible study with small sample size has been published to investigate the comparative efficacy of ATC/CPAP versus PS, ATC versus T-piece, and ATC/CPAP versus CPAP, respectively, and thus a definite conclusion could not be drawn on this point.

In this study, moreover, we also found that there were no significant differences in ICU stay, hospital stay, and hospital mortality between ATC and other groups. These indicators are not to be directly associated with SBT techniques which are implemented for a short time in the whole treatment process in ICU [19]. Hospital mortality was considered to be associated with high risk of reintubation and unsatisfactory successful separation from the ventilator. Our findings may be explained by the successful extubation rate and the reintubation rate [16], which have no significant difference between ATC and other SBT techniques groups. Similarly, definite conclusion can not be generated unless further studies with larger sample size were published.

We must acknowledge some limitations in this systematic review and meta-analysis. First, we included studies with quasi-experiment design and conference abstracts in this study, which may impair the reliability of our results. Second, most of the eligible studies were underpower due to inadequate sample size, which may reduce the robustness of pooled results. Third, some of the main clinical outcomes were only reported in few studies, and thus further studies with comprehensive outcomes should be considered. Fourth, we did not design subgroup analysis due to limit the number of eligible studies for individual outcome according to the reasons for mechanical ventilation. Fifth, some eligible studies did not describe the details of SBT technique, which will impair the value of clinical reference, and thus further studies with detailed SBT diameters are required. Sixth, some patients underwent reintubation were started on noninvasive ventilation, however we did not perform the sensitivity analysis to test the robustness of pooled results due to limited data.

\section{Conclusion}

SBT technique based on ATC, PSV, and T-piece as SBT may be considered to have comparable predictive power of successful extubation in critically ill patients. Analysis of secondary outcomes also shows no significant difference in the rate of reintubation, duration of weaning, ICU stay, hospital stay, and hospital mortality among the groups. However, a definite conclusion on this topic can not be drawn due to limited data. Therefore, we suggest designing more randomized controlled studies with large sample size to further determine the comparative efficacy of various SBT techniques.

\section{ACKNOWLEDGEMENTS}

Thanks to all the peer reviewers and editors for their opinions and suggestions to acknowledgement section.

\section{CONFLICT OF INTEREST}

The authors declare that there is no conflict of interest regarding the publication of this article.

\section{DATA AVAILABILITY}

The data used to support the findings of this study are available from the corresponding author upon request.

\section{FUNDING INFORMATION}

This research received no specific grant from any funding agency in the public, commercial, or not-for-profit sectors.

\section{REFERENCES}

[1] Dettmer MR, Damuth E, Zarbiv S, et al. Prognostic Factors for Long-Term Mortality in Critically Ill Patients Treated With Prolonged Mechanical Ventilation: A Systematic Review. Critical care medicine. 2017;45:69-74

[2] Palkar A, Mayo P, Singh K, et al. Serial Diaphragm Ultrasonography to Predict Successful Discontinuation of Mechanical Ventilation. Lung. 2018;196:363-368.

[3] Burns KEA, Raptis S, Nisenbaum R, et al. International Practice Variation in Weaning Critically Ill Adults from Invasive Mechanical Ventilation. Annals of the American Thoracic Society. 2018;15:494-502.

[4] Deab SA, Bellani G. Extubation failure after successful spontaneous breathing trial: prediction is still a challenge! Respiratory care. 2014;59:301-302.

[5] Georgakas I, Boutou AK, Pitsiou G, et al. Central Venous Oxygen Saturation as a Predictor of a Successful Spontaneous Breathing Trial from Mechanical Ventilation: A Prospective, Nested Case-Control Study. The open respiratory medicine journal. 2018;12:11-20.

[6] Chittawatanarat K, Orrapin S, Jitkaroon K, et al. An Open Label Randomized Controlled Trial to Compare Low Level Pressure Support and T-piece as Strategies for Discontinuation of Mechanical Ventilation in a General Surgical Intensive Care Unit. Medical archives (Sarajevo, Bosnia and Herzegovina). 2018;72:51-57.

[7] Guérin C, Terzi N, Mezidi M, et al. Low-pressure support vs automatic tube compensation during spontaneous breathing trial for weaning. Annals of intensive care. 2019;9:137.

[8] Lago AF, Goncalves EC, Silva EC, et al. Comparison of Energy Expenditure and Oxygen Consumption of Spontaneous Breathing Trial Conducted With and Without Automatic Tube Compensation. Journal of clinical medicine research. 2015;7:700-705.

[9] Haberthür C, Mols G, Elsasser S, et al. Extubation after breathing trials with automatic tube compensation, T-tube, or pressure support ventilation. Acta anaesthesiologica Scandinavica. 2002;46:973-979.

[10] Kashefi P, Abbasi SA, Katiraei F, et al. Comparison of the Weaning Rate in Three Mechanical Ventilation Methods, Automatic Tube Compensation and Pressure Support Ventilation with Airway Pressure of Five and Eight Centimeters of Water. اصفهان. بز شكى دانشكده مجله 2017;34:1297-1303.

[11] Wafy S, El-Shahat H, Salama S, et al. Automatic Tube Compensation Versus Pressure Support Ventilation as a Weaning Mode, Does It Make a Difference? CHEST Journal. 2015;148:312A.

[12] Burns KEA, Soliman I, Adhikari NKJ, et al. Trials directly comparing alternative spontaneous breathing trial techniques: a systematic review and meta-analysis. Critical Care. 2017;21:127. 
[13] Schmidt GA, Girard TD, Kress JP, et al. Liberation From Mechanical Ventilation in Critically Ill Adults: Executive Summary of an Official American College of Chest Physicians/American Thoracic Society Clinical Practice Guideline. Chest. 2017;151:160-165.

[14] Aggarwal AN, Agarwal R, Gupta D. Automatic tube compensation as an adjunct for weaning in patients with severe neuroparalytic snake envenomation requiring mechanical ventilation: a pilot randomized study. Respiratory care. 2009;54:1697-1702.

[15] Elbatanouny M, Abdelbary AM. Use of automatic tube compensation (ATC) for weaning from mechanical ventilation in acute respiratory failure. Egyptian Journal of Chest Diseases and Tuberculosis. 2017;66:699701.

[16] Selek Ç, Özcan PE, Orhun G, et al. The Comparison of Automatic Tube Compensation (ATC) and T-piece During Weaning. Turkish journal of anaesthesiology and reanimation. 2014;42:91-95.

[17] Higgins JPT, Thomas J, Chandler J, et al. Cochrane Handbook for Systematic Reviews of Interventions version 6.0 (updated July 2019). Cochrane, 2019. Available from www.training.cochrane. org/handbook.

[18] Moher D, Liberati A, Tetzlaff J, et al. Preferred reporting items for systematic reviews and meta-analyses: the PRISMA statement. BMJ (Clinical research ed). 2009;339:b2535.

[19] Li Y, Li H, Zhang D. Comparison of T-piece and pressure support ventilation as spontaneous breathing trials in critically ill patients: a systematic review and meta-analysis. Critical care (London, England). 2020;24:67.

[20] Higgins JPT, Altman DG, Gøtzsche PC, et al. The Cochrane Collaboration's tool for assessing risk of bias in randomised trials. BMJ (Clinical research ed). 2011;343:d5928-d5928.

[21] Olivo SA, Macedo LG, Gadotti IC, et al. Scales to assess the quality of randomized controlled trials: a systematic review. Physical therapy. 2008;88:156-175.

[22] Egger M, Davey Smith G, Schneider M, et al. Bias in meta-analysis detected by a simple, graphical test. BMJ (Clinical research ed). 1997;315:629-634.

[23] Cohen J, Shapiro M, Grozovski E, et al. Prediction of extubation outcome: a randomised, controlled trial with automatic tube compensation vs. pressure support ventilation. Critical care (London, England). 2009;13:R21.

[24] Cohen JD, Shapiro M, Grozovski E, et al. Extubation outcome following a spontaneous breathing trial with automatic tube compensation versus continuous positive airway pressure. Critical care medicine. 2006;34:682686.

[25] El-Beleidy AS, Khattab AA, El-Sherbini SA, et al. Automatic Tube Compensation versus Pressure Support Ventilation and Extubation Outcome in Children: A Randomized Controlled Study. ISRN pediatrics. 2013;2013:871376
[26] Fayed AM, El-Feky IL. Adding automatic tube compensation to continuous positive airway pressure in weaning patients with chronic obstructive pulmonary disease, is it worth trying? Critical care medicine. 2008;36:A137.

[27] Figueroa-Casas JB, Montoya R, Arzabala A, et al. Comparison between automatic tube compensation and continuous positive airway pressure during spontaneous breathing trials. Respiratory care. 2010;55:549-554.

[28] Liang CY, Chen CW, Lin WJ. A prospective, randomized comparison of automated tube compensation (ATC) and T-piece in the weaning of mechanically ventilated patients. Am J Respir Crit Care Med. 2006; 173:A41.

[29] Sherif AA, Atalaah HA. Prediction of weaning outcome, feasibility of automatic tube compensation (ATC) for weaning of chronic obstructive pulmonary disease (COPD) patients from mechanical ventilation. Anesthesia \& Analgesia. 2013;116:108.

[30] Burns KE, Lellouche F, Lessard MR, et al. Automated weaning and spontaneous breathing trial systems versus non-automated weaning strategies for discontinuation time in invasively ventilated postoperative adults. Cochrane Database Syst Rev. 2014;2014:Cd008639.

[31] Ladeira MT, Vital FM, Andriolo RB, et al. Pressure support versus T-tube for weaning from mechanical ventilation in adults. Cochrane Database Syst Rev. 2014;2014:Cd006056.

[32] Eskandar N, Apostolakos MJ. Weaning from Mechanical Ventilation. Critical Care Clinics. 2007;23:263-274.

[33] Karaca I, Comert A, Kuntman A, et al. Does automatic tube compensation change metabolic parameters when added to pressure support mode during weaning? Intensive Care Medicine Experimental. 2015;3:A321.

[34] Kuhlen R, Max M, Dembinski R, et al. Breathing pattern and workload during automatic tube compensation, pressure support and T-piece trials in weaning patients. Eur J Anaesthesiol. 2003;20:10-16.

[35] Selek Ç, Özcan PE, Orhun G, et al. The Comparison of Automatic Tube Compensation (ATC) and T-piece During Weaning. Turk J Anaesthesiol Reanim. 2014;42:91-95.

[36] Boles JM, Bion J, Connors A, et al. Weaning from mechanical ventilation. Eur Respir J. 2007;29:1033-1056.

[37] Ely EW, Baker AM, Dunagan DP, et al. Effect on the duration of mechanical ventilation of identifying patients capable of breathing spontaneously. N Engl J Med. 1996;335:1864-1869.

How to cite this article: Yu Chen, Xu Tian, Chun-Mei Luo, ShuLan Luo, Ling Lin, María F. Jiménez-Herrera. Role of Automatic Tube Compensation as Spontaneous Breathing Trial in Critically Ill Patients: A Systematic Review and Meta-Analysis. Signa Vitae. 2020;16(2):20-28. doi:10.22514/sv.2020.16.0053. 